\title{
Assessing the Genetic Impact of Headstarting and Potential for Mitigation in
}

\section{the Jamaican Iguana, Cyclura collei}

Welch, Mark E ${ }^{1}$, Armed Rasberry ${ }^{1}$, Tandora Grant ${ }^{2}$, Rick Van Veen ${ }^{4}$, Orlando Robinson $^{3}$, Dawn Fleuchaus ${ }^{5}$, and Byron Wilson ${ }^{4}$ ${ }^{1}$ Mississippi State University;, ${ }^{2}$ San Diego Zoo Institute for Conservation Research; ${ }^{3}$ Hope Zoo, Jamaica; ${ }^{4}$ University of the West Indies, Mona, Jamaica; and ${ }^{5}$ Milwaukee County Zoo

Introduction

The Jamaican iguana, Cyclura collei was once common and is now represented in the wild
by a single small population in the Hellshire Hills (see Figure 2). The population is now isted by a single small population in the Hellshire Hills (see Figure 2). The population is now Iisted
as critically Endangered by the IUCN Red List of Threatened Species, but for nearly half a century the Jamaican iguana was feared to be extinct.11) The Hellshire Hills population was

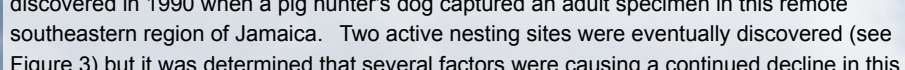
last surviving population. The major threats included predation by feral mammals and habili destrinction of until they were large enough to fend off invasive mammalian predators. Since 1991, hatchlings have been collected annualiy and raised at the Hope Zoo in Kingston. In the case of the Jamaican iguana, the program appears to have been successtul, and the number of breed
indivivuals in the Hellshire Hills is now increasing. However recent genetic research has
showe shown that the population has lost genetic variation which is causing heterozyosity levels to
decline (see figure 4). If left uncorrected, these factors could lead to increased inbreeding decline (see Figure 4). If lett uncorrectede, these factors could lead to increased inhreeding
deperession, the decline of the population, and may potentially lead to extinction. Our current goal is to determine whether this loss of genetic variation can be mitigated or even reversed
through genentic monitoring and selection of findividuals for inclusion in the headstart program. Methods

- Blood samples have been collected from wild caught hatchlings of Cyclura collei since 1991. - Samples collected between 1991 and 2009 were used for this stucy-

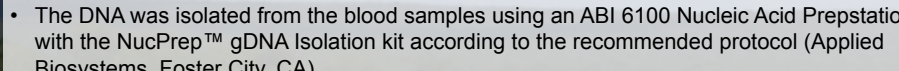
Biosystems, Foster City, CA.

- Mircosatellites, highly variable molecular markers, originally developed for other species of Allele frequencies and degree of genetic variability, heterozygosities, in each annual cohor
of hatchings and wild caught adults were estimated for comparison.

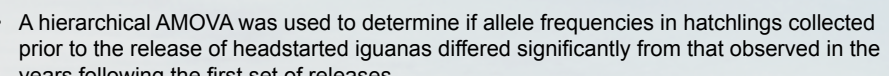



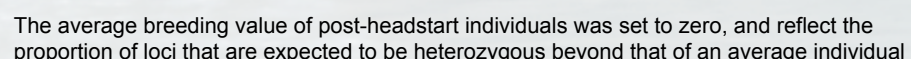
in the post-headstart population.

Results

Tweleve of 30 microsate
variable in C. colleie.

DNA was successffully isolated from a total of 375 individuals, including 11 captive
individuals currenty in US zoos, and these were genotyped via fragment analysis for six

Fragment and data analysis from the time span of 1991 to 2009 displayed a sight deccline in
average heterozygosity in the individuals collected before and after the inititition of headstart

- Hatchlings collected before the release of headstart iguanas showed an average
heterorzygosity level of 0.450 , while those in the post-headstart group displayed a d

with an average of 0.391

- The proportion of genentic variation distinguishing the two groups was 13\%, four times
greater than the degree of variation that diccerns cohorts prior to or following releases from

Analysis of Molecular
in genetic variability.

Breeding values were cal
(2002-2009) individuals

- Postheadstart breeding values were adjusted to have a mean of zero (S.D. 0.06).



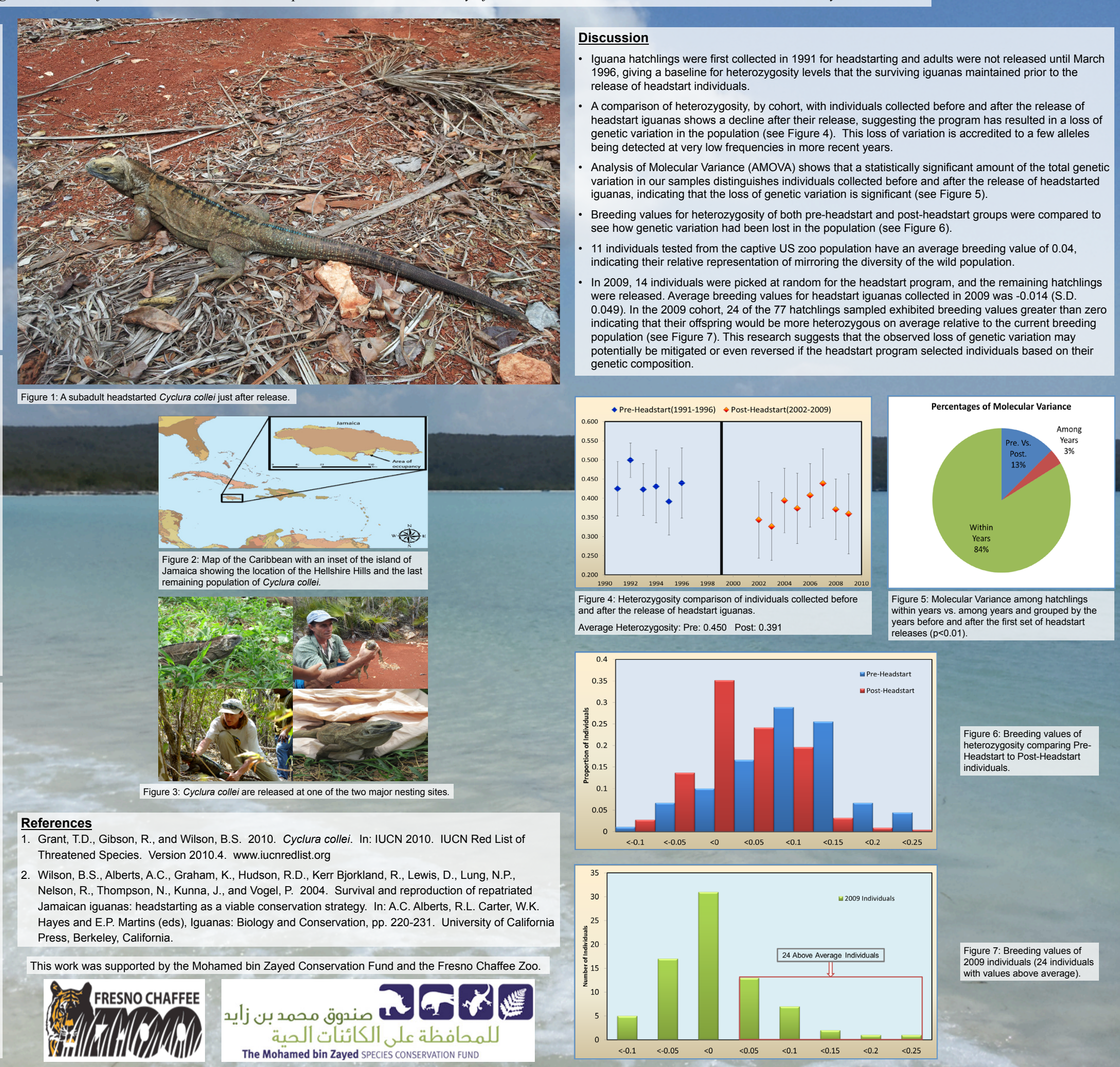

